\title{
The social justice imperative in transforming a secondary school
}

\author{
Patrick Mafora ${ }^{1 \mathrm{a}}$, \\ ${ }^{1}$ University of South Africa, PO Box 392, Pretoria, 0001, South Africa
}

\begin{abstract}
The thrust of education policy and legislation in South Africa points to a quest for democracy, equity and social justice throughout the education system. Notwithstanding, research suggests that different stakeholders experience schools as socially unjust and marginalising in some way. This article reports findings of a follow-up qualitative case study of one purposively sampled Soweto secondary school. The study sought to explore the principal's social justice leadership strategies which account for the school being perceived as democratically transformed and socially just. Data were collected through a series of in-depth semistructured interviews and observations. Data analysis followed Tesch's steps for open coding. Findings suggest that the principal's personal values and commitment to social justice principles account for his resilience in the face of resistance and systemic barriers. The principal's social justice leadership practices and barriers that he encountered are outlined.
\end{abstract}

\section{Introduction}

School principals are pivotal in ensuring that the broad goals and policy imperatives of the education ministry are given effect at school level. In South Africa school principals are members of the School Governing Bodies (SGBs) and School Management Teams (SMTs) that oversee policy formulation and the day-to-day management of the school, respectively. The South African Schools Act (hereafter SASA) mandates principals in their capacity as ex officio members of SGBs to provide guidance and advice to SGBs in the execution of their functions [36]. Such assistance should culminate in democratic and administratively sound policies that are implemented in the day-to-day management of schools. The latter is entrusted to the School Management Teams (SMTs) that are led by principals. School principals have to play a balancing act, ensuring that SGB policies they implement in daily operations are legally sound and aligned to national legislative guidelines and policy imperatives. This is, however, not always achieved. Research suggests that SGBs and

\footnotetext{
a Corresponding author: pmafora@unisa.ac.za
} 
SMTs processes overseen by principals are often characterised by undemocratic and socially unjust practices [1, 20, 28, 29 and 32]

\section{Study context and background}

This study was a follow-up on two earlier studies of five and three public secondary schools from the Soweto section of Johannesburg West District (D-12). The first study focused on SGB members' perceptions of shared decision-making and their effectiveness in the process. The second study examined the nature and manifestation of transformative leadership for social justice in township schools. The school from which the principal who is the subject of this article was drawn participated in both studies. More than any other school in these studies, this school was perceived by the majority of respondents as responsive, democratically transformed and socially just. Being a township secondary school, it falls in the category of schools that are generally considered to be dysfunctional [30;33;35], and which are characterised by, among others, violence, corporal punishment for learners, poor quality of teaching, low learner achievement, poor discipline from learners and teachers and, drug and alcohol abuse [17 and 33]. It is reasonable to expect these features to pose social justice challenges to school leaders, especially when a school has an informal settlement as one of its feeder areas. In the case of this school, the informal settlement which is its feeder area is ranked among the seven most deprived wards out of 109, in the City of Johannesburg (Patel, Korth \& Forrester, 2008). The significance of outlining this background lies in that both leadership [26] and social justice [23] are context-specific and how leaders discharge their responsibilities is reportedly influenced by student background factors like socio-economic status, ethnicity and culture [2].

This study was conceived of against this background of reported limitations in school democratisation and the social milieu of deprivation and need. The aim of the study was to determine and describe the sampled school principal's social justice leadership practices. The study also examined what constitutes the challenges and barriers to the principal's social justice leadership.

\section{Conceptual framework and related literature}

The conceptual framework that undergirds this study is social justice leadership. Literature suggests that there are multiple definitions of the concept social justice [5, 18 and 10]. This study adopted what is termed the simplistic view of the concept social justice: the opposite of injustice [10 and 25]. This notion suggests what social justice is, by pointing out that it differs from the negative that is conjured up by injustice or unjust practices. This view is close to [22] practical strand of social justice. The latter focuses on describing criteria for socially just practices in education, not theoretical or philosophical definitions. On the basis of descriptive criteria a distinction can be made between schools that are socially just and those that are not. Some of the attributes of schools that are unjust entities are that they expose members of the school community to inequalities and hurtful experiences of injustice [4], restrict freedom and inflict psychological harm through exposure to racist words, hate speech and, social oppression [3] and, allocate resources unequally thus engendering resentment, resistance, discipline problems and student low self-esteem [6]. On the other hand, schools that are socially just promote inclusion and equity, hold high expectations for all learners, develop reciprocal community relationships, and have direct social justice education and intervention [8]. They also have improved learner achievement, enhanced staff capacity, improved structures, and strengthened school cultures and communities [42]. 
It must be emphasised, though, that schools do not just evolve into just entities. Rather, they should be transformed through socially just educational leadership. In this regard, there is concurrence that social justice is inextricably linked with educational leadership [5, 34 and 39]. This suggests that leadership practices which are not grounded on social justice principles, but flout them, are morally and legally indefensible. Besides, it is unlikely that a socially just school climate can be created through unjust leadership practices. According to Chiu and Walker [9] social justice in schools is about reducing student disadvantage at the classroom, organisation, family, community and the broader society. This view gives social justice leadership an activist slant that extends beyond the confines of schools. As leaders who seek to transform their schools into socially just entities, principals should, among other attributes: be exemplary on social justice issues [42 and 43] [emphasis mine]; be open, sensitive and authentic in the treatment of teachers [21]; question institutional culture and assumptions that inform school policies and practices [5, 7 and 13]; alter inequalities related to the abuse of social power [9 and 18]; create a climate that fosters a sense of belonging to all school community members [43]; prioritise the elimination of marginalising conditions like race, class, gender, disability, sexual orientation [5, 42 and 43]; create learning opportunities and maintain high expectations of all learners [5 and 37]; encourage critical reflection on, and commitment to social justice among teachers [7 and 37].

\section{Research methods}

To answer the research questions an exploratory qualitative case study was deemed appropriate as it accommodates examining the phenomenon from the respondent's own perspective [31]. This study focused on one case, an individual secondary school principal who was purposively selected. The respondent was considered to be information-rich [27] as he was the principal of a school which was reportedly experienced by stakeholders as democratically transformed and socially just in two previous studies of five and three schools. The studies focused on shared decision-making and transformative leadership for social justice, respectively. This principal, John (a pseudonym), was just over 50 years of age. He held a three-year teachers' professional certificate and a Higher Certificate in Educational Leadership and Management. His teaching experience of more than 25 years was acquired mainly in primary schools, where he held several leadership positions. At the time of this study he was only into the third year of secondary school principalship.

Data were collected through direct observations and in-depth semi-structured interviews. These observations and interviews were grounded on, and served as follow-up to, emergent themes from the previous two studies. The interviews were deemed more appropriate for this study as they are more acceptable than questionnaires to managers who are passionate about topics that relate to their work [38]. Three interview sessions of about one hour each were conducted. The interviews were audio-recorded and subsequently transcribed. Data analysis followed Tesch's method of open coding [11 and 12].

This follow-up study was conducted within the ambit of the ethical clearance granted by the University of South Africa and permission for research granted by the Gauteng Department of Education. The respondent, gave informed consent to participate in the study and for the interviews to be recorded. The respondent participated freely with the understanding that he could withdraw from the study at any time, or decline to answer some questions, if he found it necessary to do so. 


\section{Discussion}

Findings from the study are discussed below in terms of the following three broad categories: conception of social justice leadership, social justice leadership strategies and, challenges to social justice leadership. A number of emergent sub-themes are also discussed.

\subsection{Conception of social justice leadership}

The analysis of data points to John having an understanding of what constitutes social justice leadership and an unwavering commitment to its associated principles and values. This contradicts the view that some principals ignore social justice work in preference of administrative tasks (Marshall \& Ward, 2004), or get involved in social justice work without knowing they are involved [34]. He argued that social justice leadership is a precondition for socially just teaching in schools. His explication of teaching for social justice emphasised how content, teaching methods, the teaching process, relationships, and the teacher's value system should enhance learning by challenging inequities associated with schools and their communities. His comment in this regard echoed the view that social justice is the opposite of injustice [10 and 25]. He asserted:

...teachers cannot claim to be just when it is not reflected in how they teach, how they maintain discipline, and how they interact with students, parents and other teachers. Emphasis on content alone when teachers are abusive, or ignore students' background cannot be just teaching...

It is noteworthy that John does not view social justice leadership as an abstraction, but a practice in which he as a principal is immersed, and which must be used to leverage change regarding unjust practices, both within and beyond the school [6,10 and 24]. His informative remark was:

Parents come to school all the time regarding problems they have with these learners at home. It can be anything from relationships, money, homework, you name it. We cannot chase parents away and say it is a problem for the family because if we do not assist then that problem will become our problem when it affects learning.

John's responses suggest that he shares the view that social justice leadership is a values-based practice [16, 34 and 41]. In terms of this view social justice leaders should not just implement policies passively or uncritically. Rather, their decisions should reflect a careful consideration of moral or ethical issues as well as personal and institutional values [40 and 41].

\subsection{Social justice leadership strategies}

When asked to describe his strategies for advancing social justice John pointed out that he used a repertoire of attitudes and practices that are meant "to make a difference in the lives of the school community". He argued that even in the absence of perceived injustice, he would still adopt these practices and make a difference in other ways, as "it is the right thing to do". The areas which he identified as the foci of his efforts to make a difference were students, teachers and the curriculum and, the school climate and the broader community. These are discussed separately in the next section. 


\subsubsection{Making a difference to students}

According to John he feels duty-bound to provide students with a positive learning experience that is free from discrimination, systemic abuse and deprivation. Although he supported measures for raising student achievement, he criticised the common practice of raising student achievement by tampering with their exam scores outside of the moderation process. He claimed to have resisted directives from the district office to do so. To raise student achievement, he initiated additional time for studies through Saturday morning classes and a winter vacation school. These classes are regular, inclusive and non-remedial. He maintains that giving underachieving students their own special classes stigmatises them as permanently deficient. His inclusivity drive was summed up thus:

...[poorly achieving learners] attend same classes with other learners with comparable ability [learning achievement]. It is a case of being more sensitive to their situation and accommodating them, like giving extensions for homework and project submission dates, making school facilities available for their use after school [hours], and prioritising them when learning-teaching materials are distributed. They get additional lessons only if they fall way behind... We arrange motivational talks to give learners hope that their challenges can be overcome...

Although the school is considerate to students with marginalising conditions, in line with the vision of equity of excellence [39], John maintained that the school does not have lower expectations for such students. Students with potential are usually identified and encouraged to enter local and national student competitions where knowledge, skill or competence, not background, are tested. This is meant to make them believe in themselves and that success is possible. Some trophies awarded for student achievement were displayed in the principal's office. To entrench a culture of social justice and altruism, the student code of conduct treats failure to report abuse of power, harassment, discrimination or unfair treatment, even when not perpetrated against oneself, as misconduct. All reported cases are followed through.

\subsubsection{Making a difference to teachers and the curriculum}

John reported that after his appointment as a school principal he prioritised making the school decision-making structures more broad-based and inclusive. His view is that this enhances a sense of belonging and the need to serve among teachers. To this end, in addition to the School Management Team (SMT) which comprises of the principal, deputy principals and heads of departments, he introduced a number of committees that decide on different issues that affect teachers and their work. Membership of these committees is decided by teachers themselves. To make teachers feel valued as persons, not just employees who must do their jobs, he discusses matters that affect individuals privately, not in open meetings. He said he seeks to understand possible reasons for the state of affairs before making judgements. He also tries to provide support in times of grief and celebrate individual teachers' achievements with them, even when these are not work related. This reflects the open, sensitive and authentic treatment of teachers expected from social justice leaders [21].

John maintained that he is guided by fairness and equity considerations when making decisions that involve the distribution of resources, or decisions which affect the interests and privileges of teachers. He reported that he also involves the two deputy principals or a chairperson of the relevant committee when handling matters like teacher discipline, work allocation, provision of learning teaching-materials, leave and, appraisal. To assure teachers that the decisions that are made are not personal, he provides underlying reasons and remains open to discuss their concerns. 
In line with the view that professional development is a condition for improving teaching [15] and that student learning depends on quality teaching [19] at John's school all teachers are encouraged to attend professional development workshops related to their subject fields. John facilitates attendance by making information available to all teachers and processing related documentation timeously. Several notices attesting to this were pasted on the bulletin board at the reception. To make up for lack of staff development on social justice issues, John holds informal information-sharing sessions with individual teachers. These are for mutual-reflection on social justice issues that relate to them or students.

\subsubsection{Making a difference to the community and changing school culture}

John expressed a concern that when he was appointed principal he found a schoolcommunity divide which he attributed to the fact that none of the teachers resided in that community or had children attending school there. Teachers' interaction with community members was limited or non-existent. His on-going goal was to establish positive schoolcommunity relations to foster a sense of connectedness and mutual service on which success for an organisation that pursues social justice depends [18].

He reported that he has established a community outreach initiative that, "seeks to take the school to the community and reclaim the position of the community in the school". This involves teachers visiting parents at their homes with regard to matters for which parents are normally summoned to schools like collecting report cards or discussing learner achievement, attendance, discipline or general well-being. Parents are also encouraged to visit the school whenever they can and to provide voluntary services. Maintenance jobs and once-off tasks that are paid for by the school are reserved for unemployed parents. Before the school was classified as a no-fee school, unemployed parents were allowed to render service to the school in lieu of school fees. Whenever there is a pressing need, like bereavement in a poor family, the school makes facilities available but waives the fee that is normally charged. Students from such families are on the school's free lunch programme whose meals are cooked by parents.

When there are festivities to celebrate some event, like the World Aids Day, the school invites community members, without regard for their class or status. This is attested by photos of parents mingling with teachers and students on the reception bulletin board. John remarked that his strategies would in themselves not work if the school community did not believe in him as a person before respecting him as a professional teacher and principal.

It would not be far-fetched to conclude that these strategies are an adequate base to help enhance social justice in a school as they reflect the essence of social justice leadership outlined in the foregoing conceptual framework. Specifically, these strategies cohere with Lee and McKerrow's [25] description of social justice leaders as: striving for critique rather than conformity, compassion rather than bureaucracy, polyphony rather than domination, action rather than silencing, inclusion rather than exclusion, liberation rather than domination, action for change rather than inaction that preserves inequity.

\subsection{Challenges to social justice leadership}

John viewed himself to be "one of the factors that stall social justice work" in his school. He maintained that his commitment to making a difference to others through social justice activism was hampered by the fact that he depended more on his sense of what is right and just, than on any formal training. Because of this lack of training, he was often not sure about his course of action, especially when facing resistance from staff who find his social 
justice initiatives overbearing. He conceded that at times he found it difficult to distinguish between practices which reflect ordinary lack of civility and those that are social justice infringements. Consequently, he doubts the consistency of his responses to situations and is always concerned about accusations of bias and this serves as restrictive self-censure.

Data from the series of interviews suggests that John's efforts to make a difference were met with resistance from the community, the district office, and within the school. The challenges he faced were similar to those which research suggests are generally faced by other principals attempting social justice work in different contexts [34, 42 and 43]. $\mathrm{He}$ attributed the failure of his efforts, and those of other principals, to make a difference mainly to what he termed the "abdication of the district officials" regarding their responsibilities in general, and social justice work in particular. He argued that district officials were more interested in enforcing compliance with regulations and improving learner achievement than in helping schools to address the factors that may impact negatively on learner achievement. He pointed out that district officials did not address social justice issues in the continuing professional development initiatives that they offered. Teachers were, therefore, never sensitised to the need to be social justice agents. This was complicated by what John said was a limitation in the policy framework regulating teachers. His contention was that since social justice was not mentioned as a requirement in teachers' conditions of service, it was not enforceable because non-compliance could not be sanctioned by principals. It was against this background that John argued that some teachers in his school held socially unjust beliefs and practices, and even acted them out through subtle discriminative and marginalising practices. His observation of teacher resistance to social justice was consistent with other findings [4, 34 and 42]. His informative objection to such practices was expressed thus:

We cannot say we uphold human rights and respect human dignity when some of us still want to use corporal punishment and make fun of learners' personal circumstances...

It was ironic that John reported resistance even from intended beneficiaries of his attempts to make a difference. He indicated that at times the ignorance, expectations and behaviour of some marginalised individuals tend to inhibit social justice work whenever they have come to accept their social conditions to be correct or unchangeable. The examples he cited to back his observation were instances of parents who would insist that the school should inflict corporal punishment on their children for infractions not related to the school. When the school refuses to accommodate such requests, then the parents withdraw from school activities.

\section{Conclusion}

This article examined leadership practices of one township secondary school principals with a quest to make a difference across the broader school community. A number of the principals' self-described strategies for addressing social inequities, marginalisation and injustices were outlined. The principal's success as a social justice agent challenges the view that school principals define their role only in terms of bureaucratic expectations and mandates around learner achievement. Although the article paints a picture of a principal who is committed to social justice work and is successful, findings also point to a myriad of barriers that can derail social justice efforts if unchecked. The success of this principal in the face of these barriers suggest that with commitment, adequate support structures and resources, it would be possible to overcome unquestioned social injustice challenges prevalent in schools in impoverished communities. 


\section{References}

1. Adams, F., \& Waghid, Y., In defence of deliberative democracy: Challenging less democratic school governing body practices. South African Journal of Education, 25(1): 25-33. (2005)

2. Alsbury, T. L., \& Whitaker, K.S. Superintendent perspectives and practices of accountability, democratic voice and social justice. Journal of Educational Administration, 45(2): 154-174. (2006)

3. Applebaum, B. Social justice, democratic education and the silencing of words that wound. Journal of Moral Education, 32(2): 151-162 (2003)

4. Aydin, I., \& Karaman-Kepenekci, Y. Principals' opinions of organisational justice in elementary schools in Turkey. Journal of Educational Administration, 46(4): 497-513. (2008)

5. Bogotch, I. E. Educational leadership and social justice: Practice into theory. Journal of School Leadership, 12(2): 138-156. (2002)

6. Brown, K. "New" education injustices in the "new" South Africa. Journal of Educational Administration, 44(5): 509-519 (2006)

7. Cambron-McCabe, N., \& McCathy, M. Educating school leaders for social justice. Education Policy, 1(19): 201-222 (2005)

8. Carlise, L. R., Jackson, B.W., \& George, A., Principles of social justice education: The social leadership. In Marshall, C. \& Olivia, M. (Eds). Leadership for social justice: Making revolutions in education. Boston: Pearson. (p. 16-30) (2006)

9. Chiu, M. M., \& Walker, A., Leadership for social justice in Hong Kong schools: Addressing mechanisms of inequality. Journal of Educational Administration, 45(6): 724-739 (2007)

10. Chubbuck, S. M., Individual and structural orientation in socially just teaching: Conceptualization, implementation, and collaborative effort. Journal of Teacher Education, 61(3): 197-210 (2010)

11. Creswell, J. W., Qualitative inquiry and research design: choosing among five approaches (2nd Ed.). Thousand Oaks, CA: Sage. (2007).

12. Creswell, J.W., Research design: Qualitative \& quantitative, and mixed approaches. (3rd Ed.). Thousand Oaks, CA: Sage., (2009).

13. Dantley, M., \& Tilman, L., Social justice and moral transformative leadership. In Marshall, C. \& Olivia, M. (Eds.). Leadership for social justice: Making revolutions happen (2006)

14. De Wet, T., Patel, L., Korth, M., \& Forrester, C. Johannesburg Poverty and Livelihood Study. Johannesburg: CSDA Report (2008)

15. Elmore, R.F., Bridging the gap between standards and achievement: The imperative for professional development in education. Washington, DC: Albert Shanker Institute (2002)

16. Furman, G.C., \& Shields, C.M., How can educational leaders promote and support social justice and democratic community in schools? Paper presented at the Annual Meeting of the American Educational Research Association, Chicago, 9 - 12 April (2003).

17. Gallie, M., Sayed, Y., \& Williams, H., Transforming educational management in South Africa. Journal of Negro Education, 66(4): 460-467 (1997).

18. Goldfarb, K.P., \& Grinberg, J., Leadership for social justice in education: Authentic participation in the case of a community centre in Caracas, Venezuela. Journal of School Leadership, 12: 157-173 (2002)

19. Haycock, K., Closing the achievement gap. Educational Leadership, 58(6): $6-11$ (2001) 
20. Haystek, J. School Governing Bodies - the principal's burden or the light of his or her life? South African Journal of Education, 24(4): 308-312 (2004)

21. Hoy, W.K., \& Tarter, C.J. Organisational justice in schools: No justice without trust. International Journal of Educational Management, 8(4): 250-259 (2004)

22. Hytten, K., \& Bettez, S.C. Understanding education for social justice. Educational Foundations, Winter-Spring: 7-24 (2011)

23. Johnson Fua, S. Looking towards the source - social justice and leadership conceptualisations from Tonga. Journal of Educational Administration, 45(6): 672-683 (2007)

24. Larson, C., \& Murtadha, K. Leadership for social justice, in J. Murphy (Ed.). The Educational Leadership Challenge: Redefining Leadership for the 21st Century, University of Chicago Press: Chicago, IL. (p.134 - 161) (2002)

25. Lee, S.S., \& McKerrow, K. (2005). Advancing social justice: Women's work. Advancing Women in Leadership, 19: 1-2.

26. Leithwood, K.A., \& Riehl, C. "What do we already know about successful school leadership?" Paper presented at the Annual Meeting of the American Educational Research Association, Chicago, IL, 2003 April 22. (2003)

27. Lichtman, M. Qualitative Research in Education: A user's guide. (3rd Ed.). Thousand Oaks, CA: Sage (2013)

28. Mafora, P. Shared decision-making in School Governance: A Case Study of Two Soweto Secondary Schools. The International Journal of Learning, 18(6): 97-107 (2012)

29. Mafora, P. When devolved power is recentralised: The adulteration of deliberative democracy in School Governing Bodies. Journal of Social Sciences, 34(2): 97-104 (2013)

30. Mangena, M., Demobilised education parenting. Azapo e reng? March 06 (2012)

31. McMillan, J.H., \& Schumacher, S., Research in Education: Evidence-based Inquiry. (7th Ed.). New Jersey: Pearson Education. (2010)

32. Mncube, V.S. Democratisation of education in South Africa: Issues of social justice and the voice of learners. South African Journal of Education, 28(1): 77-90, (2008)

33. Mokonyane, N., Address by the Premier at the Soweto Education Summit, Johannesburg, 09 April 2011.Available at http://www.polity.org.za/article/gpmokonyane, (2011)

34. Normore, A.H., \& Jean-Marie, G. Female secondary school leaders: At the helm of social justice, democratic schooling and equality. Leadership and Organisational Development Journal, 29(2): 182-205 (2008)

35. Pandor, N. (2006). Speech by Minister of Education, Naledi Pandor, MP, at the SADTU Conference, Johannesburg, 2006 September 01.

36. Republic of South Africa, 1996. The South African Schools Act, No. 84 of 1996. Pretoria: Government Printers.

37. Riehl, C.J. (2000). The principal's role in creating inclusive schools for diverse students: A view from a normative, empirical, and critical literature on the practice of educational administration. Review of Educational Research, 70: 55-81.

38. Saunders, M., Lewis, P. \& Thornhill, A. (2000). Research Methods for Business Students. (2nd Ed.). Essex: Pearson Education.

39. Shields, C. M. (2009). Courageous leadership for transforming schools: Democratising practice. Norwood, MA: Christopher-Gordon.

40. Starratt, R. J., (2004). Ethical Leadership, San Francisco, CA: Jossey-Bass.

41. Stevenson, H. P., (2007). A case study in leading schools for social justice: when morals and markets collide. Journal of Educational Administration, 45(6): 769 - 781. 
42. Theoharis, G. (2007). Social Justice educational leaders and resistance: Towards a theory of social justice leadership. Educational Administration Quarterly, 43(2): 221258.

43. Theoharis, G. (2010). Disrupting injustice: Principals narrate the strategies they use to improve their schools and advance social justice. Teachers' College Record, 112(1): $331-37$ 